\title{
ANALISA SISTEM INFORMASI PENJUALAN SISTEM DRIVETHRU PADA SALAH SATU RESTORAN CEPAT SAJI DI BOGOR
}

\author{
Hasanudin \\ Universitas Bina Sarana Informatika, Jakarta, Fakultas Ekonomi dan Bisnis/Akuntansi \\ Email : hasanudin.hnu@bsi.ac.id
}

\begin{abstract}
Abstrak
Sistem penjualan Drive Thru sudah cukup terkenal di Indonesia dan digunakan oleh beberapa restoran siap saji seperti : McDonald's, Kentucky Fried Chicken, Pizza Hut dan lain-lain. Sistem ini diharapkan dapat memberikan pelayanan yang cepat dan memuaskan pelanggannya, dimana saat konsumen membeli makanan seperi nasi ayam, kentang goring, hamburger dan lain-lain tidak perlu turun dari kendaraannya. Mereka cukup bertransaksi dan membayar langsung di tempat yang telah disediakan. Sistem ini tentu sangat menarik perhatian untuk dijadikan percontohan untuk usaha-usaha lainnya. Oleh karena itu, penulis mencoba menganalisa sistem penjualan Drive Thru tersebut. Setelah dianalisa diketahui bahwa sistem terebut masih memiliki beberapa permasalahan yang perlu jadi perhatian, diantaranya yaitu adanya keluhan konsumen karena kru restoran lambat respons. Selain itu terdapat masalah kurangnya efisien waktu karena pada saat crew tersebut melakukan proses payment tidak bisa melakukan order product dalam waktu bersamaan, akibatnya customer antrian selanjutnya harus menunggu hingga customer pertama selesai melakukan payment dan otomatis antrian kebelakang akan lebih panjang ketika sedang ramai pengunjung.
\end{abstract}

Kata kunci: sistem, sistem informasi penjualan, drive thru

\begin{abstract}
The Drive Thru sales system is quite well known in Indonesia and is used by several fast food restaurants such as: McDonald's, Kentucky Fried Chicken, Pizza Hut and others. This system is expected to provide fast service and satisfy its customers, where when consumers buy food such as chicken rice, fried potatoes, hamburgers, etc., they do not need to get off the vehicle. They simply transact and pay directly in the space provided. This system is certainly very attractive to be used as an example for other businesses. Therefore, the authors try to analyze the Drive Thru sales system. After being analyzed, it is known that the system still has several problems that need attention, including consumer complaints because the restaurant crew is slow to respond. In addition, there is a problem of lack of time efficiency because when the crew performs the payment process they cannot order the product at the same time, as a result the next queue customer has to wait until the first customer has finished making the payment and automatically the back queue will be longer when there are many visitors.
\end{abstract}

Keywords: system, sales information system, drive thru 


\section{PENDAHULUAN}

Pada era perkembangan teknologi informasi saat ini telah membawa banyak perubahan bagi masyarakat sebagai pengguna informasi. Komputer yang memegang peranan sangat penting dalam penyebaran informasi, juga memegang peranan dalam mengolah, menyimpan, dan menghasilkan informasi. Demikian halnya manajemen di suatu perusahaan, banyak keuntungan yang diperoleh terutama dalam hal kemudahan dan keefesienan tenaga dan waktu.

Dalam setiap perusahaan, teknologi komputer dan perkembangan informasi menjadi salah satu faktor utama kemajuan sebuah perusahaan dan tentunya harus berkembang dengan baik. Selain itu sarana pendukung lainnya seperti peralatan dan Sumber Daya Manusia (SDM) harus disiapkan seiring dengan semakin canggihnya teknologi informasi.

Sistem penjualan menggunakan Drive Thru adalah sistem yang sudah terkomputerisasi dimana pembeli dapat dengan mudah memesan tanpa antri, cukup memesan di dalam mobil pada layar box yang sudah disediakan.

Oleh karena itu, untuk menyesuaikan diri dengan perkembangan zaman, perusahaan-perusahan yang bertujuan bisnis maupun pelayanan masyarakat yang berada di Indonesia mulai berkembang dan mempercanggih cara penanganan kepada calon nasabah mereka dengan mengaplikasikan berbagai sistem yang mereka miliki ke media komputer, dengan kata lain pengaplikasian sistem transaksi penjualan yang berbasis komputer. Selain mempercepat kinerja perusahaan juga bisa mengefesiensikan pengeluaran biaya atau penekanan terhadap pengeluaran lainnya.

Dalam hal ini penulis membahas tentang sistem pemesanan makanan melalui Drive Thru pada Perusahaan McDonald's Semplak Bogor, mulai dari pemesanan oleh konsumen sampai dengan pembayaran. Adapun pembahasan tersebut akan dituangkan dalam bentuk laporan riset dengan judul : "Analisa Sistem Penjualan Sistem Drive Thru Pada Salah satu Restoran Siap Saji di Bogor".

\section{RUMUSAN MASALAH}

Rumusan masalah dalam penelitian ini adalah membahas analisa system berjalan tentang pelayanan penjulan menggunakan sistem drive thru agar tetap bisa memberikan pelayanan yang maksimal dan lebih cepat.

Adapun ruang lingkup yang penulis bahas dalam penulisan laporan riset ini mengarah pada penjualan hingga pembayaran di restoran siap saji ini. Hal ini akan dijadikan suatu proses laporan kepada pimpinan untuk menentukan kebijakan dalam mengambil suatu keputusan perusahaan.

Restoran siap saji adalah rangkaian rumah makan siap saji terbesar di dunia. Hidangan utama di restoran-restoran McDonald's adalah hamburger, namun mereka juga menyajikan minuman ringan, kentang goreng, filet ayam dan hidanganhidangan lokal yang di sesuaikan dengan tempat restoran itu berada.

\section{TINJAUAN PUSTAKA}

\section{Konsep Dasar Sistem Informasi}

Dalam memahami suatu sistem, kita harus terlebih dahulu mengetahui apa pengertian dari sistem itu sendiri, baru kemudian memahami sistem secara lebih dalam mengenai karakteristik sistem, klasifikasi sistem dan siklus hidup sistem.

Menurut Supriyadi dkk dalam Jurnal CCIT (2013:310), "Sistem adalah sekumpulan unsur atau elemen yang saling berkaitan dan saling mempengaruhi dalam melakukan kegiatan bersama untuk mencapai suatu tujuan".

Menurut Azhar Susanto (2013:22), "Sistem adalah kumpulan/ group dari sub sistem/ bagian/ komponen apapun baik pisik atau pun non pisik yang saling berhubungan satu sama lain dan bekerja 
sama secara harmonis untuk mencapai satu tujuan tertentu".

Menurut Azhar Susanto (2013:72) dalam bukunya yang berjudul "Sistem Informasi Akuntansi adalah kumpulan atau group dari sub sistem/ komponen/ bagian apapun baik phisik/ non phisik yang saling berhubungan satu dengan yang lainnya dan bekerja sama secara harmonis untuk mengolah data transaksi yang berkaitan dengan masalah keuangan menjadi informasi keuangan".

Menurut Wijayanto dalam Mardi (2014). "Sistem Informasi Akuntansi adalah susunan berbagai dokumen, alat komunikasi, tenaga pelaksana, dan berbagai laporan yang didesain untuk mentransformasikan data keuangan menjadi informasi keuangan".

\section{Sistem Penjualan Drive Thru}

Sistem informasi akuntansi ini memilih penjualan melalui Drive Thru Semplak Bogor di perusahaan yang dikategorikan sebagai makanan junk food, untuk kami analisa sehingga menjadi sebuah laporan.

Penjualan (sales) adalah aktivitas atau bisnis menjual produk atau jasa. Dalam proses penjualan, penjual atau penyedia barang dan jasa memberikan kepemilikan suatu komoditas kepada pembeli untuk suatu harga tertentu.

Drive Thru (Drive Through) merupakan layanan yang mana kamu bisa mendapatkan makanan tanpa harus keluar dari mobil. Dengan kata lain, kamu bisa memesan makanan atau minuman hanya dengan membuka kaca jendela mobil.

Junk Food adalah istilah yang mendeskripsikan makanan yang tidak sehat atau memiliki sedikit kandungan nutrisi. Makanan yang mengandung jumlah lemak yang besar. Makanan cepat saji seperti hamburger, kentang goreng dari McDonald's, KFC dan Pizza Hut sering dianggap sebagai makanan yang jumlah lemaknya besar, sementara makanan yang sama seperti California
Pizza Kitchen atau Nando's tidak dianggap, meskipun nutrisi yang dimilikinya hampir sama. Bagi yang sedang menderita pirai atau memiliki kadar asam urat yang tinggi, disarankan untuk menghindari jenis-jenis makanan tersebut.

\section{Unified Modeling Language (UML)}

UML merupakan singkatan dari "Unified Modelling Language" yaitu suatu metode permodelan secara visual untuk sarana perancangan sistem berorientasi objek, atau definisi UML yaitu sebagai suatu bahasa yang sudah menjadi standar pada visualisasi, perancangan dan juga pendokumentasian sistem software. Saat ini UML sudah menjadi bahasa standar dalam penulisan blue print software

Karena kebanyakan metodologimetodologi yang berkembang pesat saat itu, maka muncullah ide untuk membuat sebuah bahasa yang dapat di mengerti semua orang. Usaha penyatuan ini banyak mengambil dari metodologi-metodologi yang berkembang saat ini, maka dibuat bahasa yang merupakan gabungan dari beberapa konsep seperti konsep Object Modelling Technique (OMT) dari Rumbaugh dan Booch (1991), konsep The Classes, Responsibilities, Collaborators (CRC) dari Rebecca Wirfs-Brock (1990), konsep James R. Rumbaigh, Grady Booch, dan Ivar Jacobson bergabung dalam sebuah perusahaan yang bernama Rational Software Corporation menghasilkan bahasa yang disebut dengan Unified Corporation menghasilkan bahasa yang disebut dengan Unified Modeling Language (UML).

Pada 1996, Object Management Group (OMG) mengajukan proposal agar adanya standardisasi pemodelan berorientasi objek dan pada bulan September 1997 UML diakomodasi oleh OMG sehingga sampai saat ini UML telah memberikan kontribusinya yang cukup besar di dalam metodologi berorientasi 
objek dan hal-hal yang terkait di dalamnya.

Secara fisik, UML adalah sekumpulan spesifikasi yang di keluarkan oleh OMG. UML terbaru adalah UML 2.3 yang terdiri dari 4 macam spesifikasi, yaitu Diagram Interchange Specification, UML Infrastructure, UML Superstructure, dan Objek Constraint Language (OCL).

Suatu alat yang digunakan untuk menggambarkan bentuk logika model dari suatu sistem dengan menggunakan simbolsimbol, lambang-lambang, berupa diagram-diagram yang menunjukkan secara tepat arti dan fungsinya. Ada beberapa jenis diagram UML diantaranya, class diagram, package diagram, use case diagram, sequence diagram, communication diagram, state chart diagram, activity diagram, component diagram, dan deployment diagram.

\section{Jenis-jenis Diagram Unified Modeling Language (UML) \\ 1. Class Diagram}

Bersifat statis. Diagram ini memperlihatkan himpunan kelaskelas, antarmuka-antarmuka, kolaborasi-kolaborasi dan relasirelasi.

\section{Package Diagram}

Bersifat statis. Diagram ini memperlihatkan kumpulan kelaskelas, merupakan bagian dari diagram komponen.

\section{Use Case Diagram}

Bersifat statis. Diagram ini memperlihatkan himpnan use case dan aktor- aktor (suatu jenis khusus dari kelas).

\section{Sequence Diagram}

Bersifat dinamis. Diagram urutan adalah diagram interaksi yang menekankan pada pengiriman pesan dalam waktu tertentu.

\section{Communication Diagram}

Bersifat dinamis. Diagram sebagai pengganti diagram kolaborasi UML 1.4 yang menekankan organisasi struktural dari objek-objek yang menerima serta mengirim pesan.

\section{State Chart Diagram}

Bersifat dinamis. Diagram status memperlihatkan keadaan-keadaan pada sistem, memuat status (state), transisi, kejadian serta aktifitas.

\section{Activity Diagram}

Bersifat dinamis. Diagram aktivitas adalah tipe khusus dari diagram status yang memeperlihatkan aliran dari suatu aktivitas ke aktivitas lainnya dalam suatu sistem.

\section{Component Diagram}

Bersifat statis. Diagram komponenini memperlihatkan organisasi kebergantungan sistem/perangkat lunak pada komponen-komponen yang telah ada sebelumnya.

\section{Deployment Diagram}

Bersifat statis. Diagram ini memperlihatkan konfigurasi saat aplikasi dijalankan (run-time).

\section{Use Case Diagram}

Use case adalah kegiatan atau urutan interaksi yang saling berkaitan antara sistem dan aktor. Use case bekerja dengan cara mendeskripsikan tipe interaksi antara user sebuah sistem dengan sistemnya sendiri melalui sebuah cerita bagaimana sebuah sistem dipakai. Use case juga digunakan untuk membentuk perilaku (behaviour) sistem yang akan dibuat. Sebuah use case menggambarkan sebuah interkasi antara pengguna (aktor) dengan sistem yang ada.

Syarat Penamaan pada Use Case adalah nama didefinisikan sesimpel mungkin dan dapat dipahami. Ada dua hal utama pada Use Case yaitu pendefinisian apa yang disebut aktor dan Use Case:

1. Aktor merupakan orang, proses atau sistem lain yang berinteraksi dengan sistem informasi yang akan dibuat diluar sistem informasi yang akan dibuat itu sendiri, jadi walaupun simbol dari aktor adalah 
gambar orang, tapi aktor belum tentu merupakan orang.

2. Use case merupakan fungsionalitas yang disediakan sistem sebagai unit-unit yang saling bertukar pesan antar unit atau aktor.

Berikut adalah simbol-simbol yang dipakai untuk membuat use case diagram, sebagai berikut :

Tabel 1. Simbol-simbol usecase diagram

\begin{tabular}{|c|c|c|}
\hline SI & NAMA & KETERANGAN \\
\hline & Actor & $\begin{array}{l}\text { Menspesifikasikan himpuan peran yang } \\
\text { pengguna mainkan ketika berinteraksi } \\
\text { dengan use case. }\end{array}$ \\
\hline & Dependency & $\begin{array}{l}\text { Hubungan dimana perubahan yang terjadi } \\
\text { pada suatu elemen mandiri (independent) } \\
\text { akan mempengaruhi elemen yang } \\
\text { bergantung padanya elemen yang tidak } \\
\text { mandiri. }\end{array}$ \\
\hline$\leftarrow$ & Generalization & $\begin{array}{l}\text { Hubungan dimana objek anak (descendent) } \\
\text { berbagi perilaku dan struktur data dari objek } \\
\text { yang ada di atasnya objek induk (amcestor). }\end{array}$ \\
\hline & Include & $\begin{array}{l}\text { Menspesifikasikan bahwa use case sumber } \\
\text { secara eksplisit. }\end{array}$ \\
\hline & Extend & $\begin{array}{l}\text { Menspesifikasikan bahwa use case target } \\
\text { memperluas perilaku dari use case sumber } \\
\text { pada suatu titik yang diberikan. }\end{array}$ \\
\hline & Association & $\begin{array}{l}\text { Apa yang menghubungkan antara objek satu } \\
\text { dengan objek lainnya. }\end{array}$ \\
\hline & System & $\begin{array}{l}\text { Menspesifikasikan paket yang } \\
\text { menampilkan sistem secara terbatas. }\end{array}$ \\
\hline & Use Case & $\begin{array}{l}\text { Deskripsi dari urutan aksi-aksi yang } \\
\text { ditampilkan sistem yang menghasilkan suatu } \\
\text { hasil yang terukur bagi suatu aktor. }\end{array}$ \\
\hline & Collaboration & $\begin{array}{l}\text { Interaksi aturan-aturan dan elemen lain yang } \\
\text { bekerja sama untuk menyediakan prilaku } \\
\text { yang lebih besar dari jumlah dan elemen- } \\
\text { elemennya (sinergi). }\end{array}$ \\
\hline & Note & $\begin{array}{l}\text { Elemen fisik yang eksis saat aplikasi } \\
\text { dijalankan dan mencerminkan suatu sumber } \\
\text { daya komputasi. }\end{array}$ \\
\hline
\end{tabular}

Sumber : www.kajianpustaka.com

\section{Activity Diagram}

Activity diagram adalah representasi grafis dari workflow dari kegiatan dan tindakan bertahap dengan dukungan untuk pilihan, iterasi dan concurrency. Dalam Unified Modeling Language (UML), activity diagram dimaksudkan untuk model kedua proses komputasi dan organisasi (yaitu workflow). Activity diagram menunjukkan aliran keseluruhan kontrol.
Diagram aktivitas juga banyak digunakan untuk mendefinisikan hal-hal berikut :

1. Rancangan proses bisnis dimana setiap urutan aktivitas yang digambarkan merupakan proses bisnis sistem yang didefinisikan.

2. Urutan atau pengelompokan tampilan dari sistem / user interface dimana setiap aktivitas di anggap memiliki sebuah rancangan antar muka tampilan.

3. Rancangan pengujian dimana setiap aktivitas dianggap memerlukan sebuah pengujian yang perlu di definisikan kasus ujinya.

4. Rancangan menu yang ditampilkan pada perangkat lunak.

Berikut adalah simbol-simbol yang dipakai untuk membuat activity diagram, sebagai berikut :

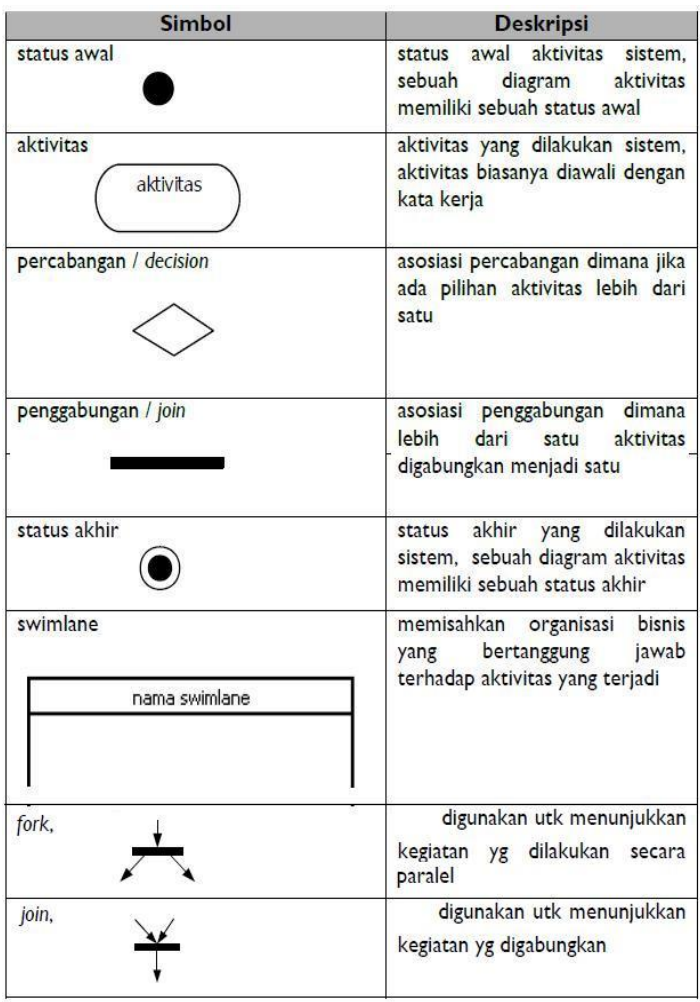

\section{HASIL DAN PEMBAHASAN}

\section{Prosedur Sistem Berjalan}

Pada bagian ini penulis ingin menguraikan secara umum prosedur 
sistem berjalan yang ada pada restoran khususnya pada bagian sistem penjualan melalui Drive Thru. Adapun prosedur sistem berjalan yang ada pada restoran adalah :

\section{Login Number Crew}

Setiap crew restoran masing-masing memiliki nomer id, nomer id setiap crew berbeda satu sama lain. Nomer id berguna untuk masuk kesetiap pos register, jika nomer id tidak dimasukan maka pos register tidak dapat digunakan. Setiap crew bertanggung jawab pada pos register yang login dengan nomer id nya.

\section{Greeting}

Setiap crew yang nomer id nya sedang login wajib greeting (memberi salam/ sambutan) kepada customer. Contoh : selamat siang, selamat datang di restoran, silahkan pesanannya

\section{Order Product}

Customer akan memberikan pesanannya pada crew yang bertugas, dan crew yang bertugas akan menginput pada pos register yang login dengan nomer id nya.

4. Key In Product

product customer di input di pos register.

\section{Payment}

Pembayaran terbagi menjadi dua, yaitu : tunai dan non tunai. Tunai, customer hanya tinggal memberikan uang sejumlah total harga produk yang diorder. Sedangkan non tunai, dengan kartu credit atau debet, crew tinggal me-swep kartu credit atau debet customer di mesin EDC yang tersedia.

\section{Cetak Struk}

Setelah pembayaran selesai struk order dapat di berikan kepada customer sebagai bukti transaksi.

\section{Use Case Diagram Sistem Berjalan}

Berikut adalah Use Case diagram sistem berjalan pada sistem penjualan sistem Drive Thru restoran tersebut:

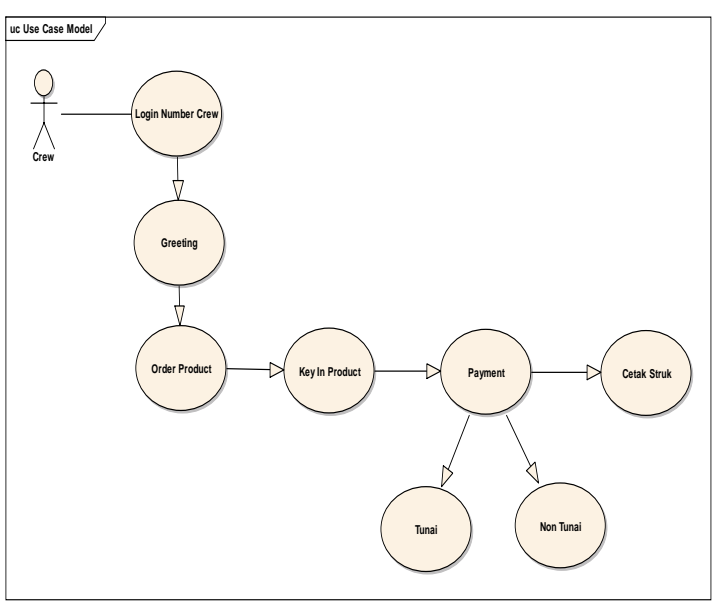

Gambar 1. Use Case sistem berjalan

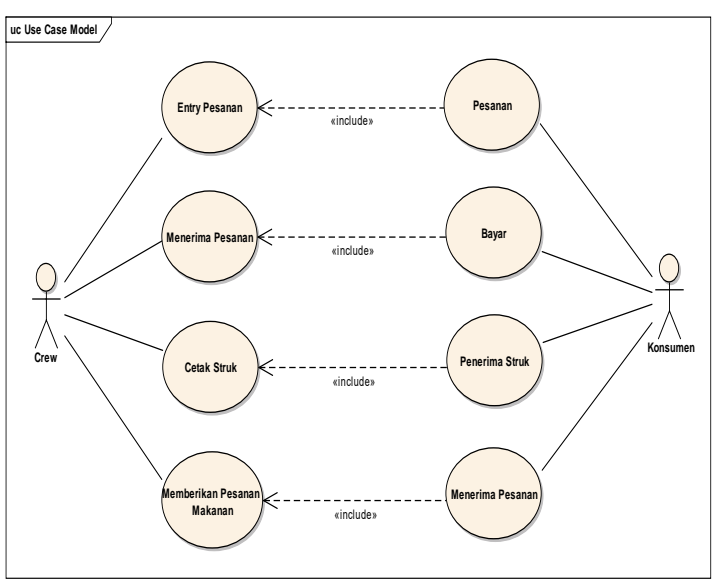

\section{Gambar 2. Use Case model sistem berjalan}

\section{Activity Diagram Sistem Berjalan}

Berikut adalah Activity diagram sistem berjalan pada sistem penjualan melalui Drive Thru restoran tersebut: 


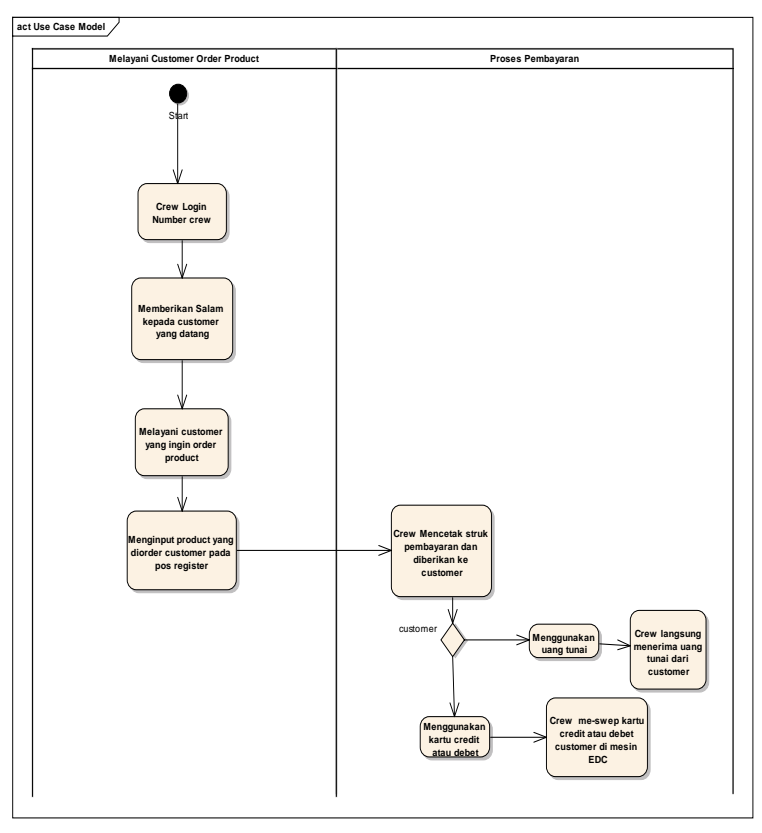

\section{Gambar 3. Activity Diagram Sistem Berjalan}

\section{Spesifikasi Bentuk Dokumen Masukan}

Dokumen input pada penulisan ini adalah semua bentuk dokumen yang masuk kesebuah sistem perusahaan yang berasal dari lingkungan perusahaan tersebut baik dari dalam maupun dari luar, yang berupa dokumen-dokumen yang akan diolah dalam suatu proses agar dapat menghasilkan keluaran yang sesuai dengan yang di inginkan :

1. Struk Copy

$\begin{array}{ll}\text { Nama Dokumen } & \text { : Struk Copy } \\ \text { Fungsi } & \begin{array}{l}\text { :Sebagai } \\ \text { pembayaran } \\ \text { :Bagian } \\ \text { Sumber }\end{array} \\ \text { pembayaran kasir } \\ \text { Tujuan } & \text { : Keuangan } \\ \text { Media } & : \text { Kertas } \\ \text { Jumlah } & : 5 \text { ply } \\ \text { Frekuensi } & : \text { Setiap hari } \\ \text { Bentuk } & : \text { Kertas thermal }\end{array}$

\section{Spesifikasi Bentuk Dokumen Keluaran}

Dokumen keluaran dihasilkan berdasarkan hasil pengolahan dari dokumen masukkan adapun bentuk dokumen yang dihasilkan sebagai berikut:

1. Struk Asli

$\begin{array}{ll}\text { Nama Dokumen } & \begin{array}{l}\text { : Struk Asli } \\ \text { Fungsi }\end{array} \\ \begin{array}{l}\text { Sebagai } \\ \text { pembayaran }\end{array} \\ \text { Sumber } & \text { Bagian kasir } \\ \text { Tujuan } & \text { : Customer } \\ \text { Media } & \text { : Kertas } \\ \text { Jumlah } & : 5 \text { ply } \\ \text { Frekuensi } & \text { : Setiap hari } \\ \text { Bentuk } & \text { : Kertas thermal }\end{array}$

\section{Spesifikasi Perangkat Lunak}

Sistem Point Of Sales (POS), Restoran pertama di seluruh dunia yang menggunakan sistem ini adalah pada tahun 1974. Sistem ini digunakan dengan kode angka untuk tiap menu yang dipesan, lalu mesin tersebut akan menghitung jumlah uang yang harus dibayarkan, kurang lebih sama prinsipnya dengan yang biasa digunakan di mesin kasir pada umumnya. Perhitungan pajak restoran juga ditambahkan ke dalam mesin sesuai dengan peraturan pemerintah.

Beberapa komputer disambungkan pada satu sistem data utama dengan satu opsi yang disebut Manager Mode, sehingga saat satu perangkat rusak, sistem data utama tetap akan mem-back-up data di perangkat tersebut.

Setiap store restoran ini mempunyai suatu software yang bisa dikategorikan sebagai sistem informasi dimana software tersebut terhubungkan dengan suatu Par Register yang berfungsi menjadi interface antara user yang dalam hal ini adalah crew counter dan pemasukkan atau pencatatan pesanan customer atau pelanggan. Seiring berjalannya waktu dalam perkembangannya, restoran mengganti $S I$ par register dengan SI POS (Point Of Sale) untuk mesin kasir yang digunakan, dikarenakan POS mempunyai piranti penyimpanan data sendiri sehingga data transaksi dapat tersimpan dengan baik dan dapat dilihat kembali, dengan kata lain penggunaan POS ini diperuntukkan agar tidak terjadi kehilangan data transaksi. 
Dalam pengolahan data yang masih menekankan pada operasi manual, sudah dapat dipastikan tidak menghemat waktu, bahkan terkadang sering timbul human error sehingga data-data tidak terdeteksi sehingga menjadi error atau kurang akurat, maka sekarang ini dibuatlah Program SMS (Store Management System) yang fungsinya adalah sebagai pengolah datadata transaksi hasil par register maupun POS. Program ini pun menyimpan history 1 tahun kebelakang, sehingga kita dapat membuka data-data yang nanti akan dipakai.

\section{Spesifikasi Perangkat Keras}

Sebuah sistem dengan perangkat lunak tercanggih tidaka akan dapat bekerja tanpa adanya sebuah perangkat keras atau hardware. Keterpaduan antara perangkat keras yang ada sangat dibutuhkan agar hasil kinerja dari sistem komputer dapat berjalan semaksimal mungkin untuk menunjang sistem kerja yang sudah dirancang. Berikut adalah beberapa hardware yang digunakan pada sistem Drive Thru McDonal's :

$\begin{array}{lll}\text { 1. } & \text { Mesin Kasir : Touchscreen Layar } \\ \text { 2. } & \text { Mentuh Dx-915 } \\ \text { Monitor Daftar produk } & : \\ \text { QSR luar signage digital } & \\ \text { 3. Monitor Display Terminal } & : 18 \text { " } \\ \text { 4. HeadPhone } & : \\ \text { 5. } & \text { Input Microphone } & :-60 \\ \text { 6. Spv } & \\ \text { 6. Speaker output }\end{array}$

\section{Permasaalahan Pokok}

Setelah melihat dan mempelajari sistem yang berjalan, maka penulis mencoba menguraikan permasalahan yang ada pada penjualan melalui Drive Thru di restoran. Secara keseluruhan, sistem penjualan yang di gunakan pada umumnya telah berjalan dengan baik, dan sistem penjualan yang digunakan untuk pemesanan sudah diperbaiki menjadi lebih mudah. Hanya saja dalam proses penjualan masih saja ada customer yang komplen karena lambatnya respon dari crew.

Hal tersebut disebabkan karena ada beberapa aktivitas yang dikerjakan oleh satu orang crew. Aktivitas tersebut yaitu pada bagian Order Product dan payment dikerjakan oleh hanya satu orang crew. Kurangnya efisien waktu karena pada saat crew tersebut melakukan proses payment tidak bisa melakukan order product dalam waktu bersamaan, akibatnya customer antrian selanjutnya harus menunggu hingga customer pertama selesai melakukan payment dan otomatis antrian kebelakang akan lebih panjang ketika sedang ramai pengunjung.

\section{Pemecahan Masalah}

Dalam era sistem informasi, tidak ada suatu sistem yang benar-benar terhindar dari suatu permasalahan. Terkadang membuat pelayanan dalam suatu proses penjualan dan pembelian yang sering kali terjadi masalah, tetapi masalah tersebut setidaknya dapat ditekan seminimal mungkin.

Untuk itu alternatif pemecahan masalah yang penulis usulkan adalah dengan ditambahnya crew sehingga setiap aktivitas dilakukan oleh crew yang berbeda. Hal tersebut dapat berperngaruh pada efisien waktu karena jika pada saat bagian payment menerima pembayaran dari customer dalam waktu bersamaan bagian Order Product bisa melayani pesanan antrian selanjutnya. Karena tujuan utama pada sistem Drive Thru ini adalah kepraktisan maka customer seharunya dilayani dengan waktu yang singkat.

Tujuan alternatif pemecahan masalah adalah untuk mengatasi masalahmasalah yang ada. Adapun manfaat dari pemecahan masalah ini, sebagai berikut :

\section{Mengurangi antrian pada boot} pemesanan

2. Mengurangi customer yang komplen 
3. Memudahkan crew dalam melayani customer

\section{KESIMPULAN DAN SARAN}

\section{Kesimpulan}

Berdasarkan riset keputusan dan riset lapangan yang penulis lakukan maka secara umum dapat menyimpulkan beberapa hal sebagai berikut :

1. Secara keseluruhan, sistem penjualan yang di gunakan pada umumnya telah berjalan dengan baik, dan sistem penjualan yang digunakan untuk pemesanan sudah diperbaiki menjadi lebih mudah.

2. Terdapat beberapa kekurangan dalam sistem pelayanan yang dapat berakibat munculnya complain ketidak puasan customer atas pelayanan yang diberikan oleh sistem Drive Thru ini.

3. Beberapa complain dikarenakan kurangnya crew untuk menunjang sistem penjualan Drive Thru pada McDonal's yang berakibat crew lambat merespon pesanan dari customer karena satu crew mengerjakan beberapa aktivitas sekaligus.

\section{Saran-Saran}

Agar sistem penjualan pemesanan makanan melalui Drive Thru dapat di gunakan dengan baik, penulis memberikan saran sebagai usulan agar sistem yang sudah dirancang sedemikian rupa dapat berjalan dengan baik. Oleh karena itu penulis menyarankan agar ditambahnya crew sehingga setiap aktivitas dilakukan oleh crew yang berbeda.

Hal tersebut dapat berperngaruh pada efisien waktu karena jika pada saat bagian payment menerima pembayaran dari customer dalam waktu bersamaan bagian Order Product bisa melayani pesanan antrian selanjutnya. Karena tujuan utama pada sistem Drive Thru ini adalah kepraktisan maka customer seharunya dilayani dengan waktu yang singkat.

\section{REFERENSI}

A.S, Rosa et al., 2016, "Rekayasa Perangkat Lunak", Penerbit Informatika, Bandung

Milawati Hartono. Pengertian, Komponen Dan Contoh Use Case Diagram di ambil dari:

https://milawatihartono.wordpress.co m/2016/03/31/use-case-diagram/ (02 April 2018)

Munawar, 2017, “Analisa Perancangan Sistem Berorientasi Objek dengan UML", Penerbit Informatika, Bandung

Pahmi Ritonga. Pengertian Activity Diagram di ambil dari: http://www.bangpahmi.com/2013/06/ activity-diagram.html (02 April 2018)

Tohri, Hamin, 2017, “Analisis serta Perancangan Sistem Informasi melalui Pendekatan UML", Penerbit Andi Offset, Jakarta

TMBooks, 2015, "Sistem Informasi Akuntansi", Penerbit Andi Offset, Jakarta

Munawar, 2017, “Analisa Perancangan Sistem Berorientasi Objek dengan UML", Penerbit Informatika, Bandung

Yani, Ahmad, 2006, "Solusi Masalah Pajak Pertambahan Nilai", Penerbit Kencana Prenada Media Group, Jakarta 
Hasanudin, Analisa Sistem Informasi Penjualan Sistem Drive Thru... 